\title{
LOS RELATOS ERÓTICOS DE MAROSA DI GIORGIO: EXTRAÑEZA POÉTICA Y CRÍTICA EPISTEMOLÓGICA
}

The erotic stories of Marosa di Giorgio: poetic strange and epistemological criticism

\author{
MARÍA TERESA AEDO FUENTES \\ Universidad de Concepción (Chile) \\ maaedo@udec.cl
}

Esta solo es una vida, no mi vida. La vida que está en mí no responde a mi nombre: yo solo es algo transitorio

Rosi Braidotti

\section{Resumen}

Propongo una lectura de los relatos eróticos de Di Giorgio, según este, el hibridismo genérico textual y sexual ampliamente reconocido por la crítica, así como la recurrencia de transformaciones y metamorfosis a impulsos de un deseo que cancela las fronteras entre lo humano, lo animal, lo vegetal y lo material, realiza una profunda crítica epistemológica a la racionalidad moderna, andro y antropocéntrica, y su forma de concebir identidad y diferencia. El eje de esta ruptura epistemológica es la desarticulación de las estructuras binarias sexo/género y Naturaleza/Cultura, que disloca la alineación de cuerpo-género-deseo y la oposición clásica bios/zoé, bases fundamentales de los órdenes políticos y simbólicos de Occidente.

Palabras clave: Marosa di Giorgio; relatos eróticos; des-género.

\section{Abstract}

I propose a reading of Di Giorgio's erotic stories according to which generic textual and sexual hybridism widely recognized by critics, as well as the recurrence of transformations and metamorphosis at the urging of a desire that cancels the boundaries between the human, animal, vegetable and material, he makes a deep epistemological critique of modern rationality, andro and anthropocentric, and his way of conceiving identity and difference. The axis of this epistemological rupture is the disarticulation of the sex/gender and nature/culture binary structures, which dislocate the alignment of body-gender-desire and the classic bios/zoé opposition, fundamental bases of the political and symbolic orders of the West.

Key words: Marosa Di Giorgio; erotic stories; des-gender.

\section{HIBRIDISMO GENÉRICO TEXTUAL Y SEXUAL}

La crítica literaria respecto de la obra de la escritora uruguaya Marosa di Giorgio coincide en resaltar su hibridismo genérico textual y genérico sexual (Echavarren, 1992; Olivera-Williams, 2005; Vásquez, 2008; Bruña, 2010; Ferrús, 2011), así como la recurrencia de transformaciones y metamorfosis que vuelven difusos los límites entre 


\section{María Teresa Aedo Fuentes}

los órdenes de realidad-sueño-fantasía y suprimen las fronteras entre lo humano, lo animal, lo vegetal, lo material a impulsos de un deseo arrollador que atrae incesantemente a los cuerpos sexuados y erotizados.

Así por ejemplo, María José Bruña la destaca como cultivadora de un "hibridismo conceptual, genérico y formal" (2010, p. 223), mientras Beatriz Ferrús habla de géneros dudosos:

Si el género es la escenificación social, cultural del sexo, Marosa di Giorgio pone en escena un género que solo puede ser dudoso, pues sus relatos desafían las convenciones sociales, la Normalidad, para demostrar que esta es solo una construcción, una versión de las muchas posibles. La textualidad se contagia de la apuesta ideológica y el género literario también deviene dudoso, puesto que poesía y narrativa aniquilan sus fronteras (Ferrús, 2011,p. 8).

La difuminación de límites tan característica de la escritura de Di Giorgio sugiere para Ferrús que

El universo marosiano con sus propias reglas y sus fronteras difuminadas deviene el espacio perfecto para indagar la identidad contemporánea como encrucijada, donde el género, la identificación nacional, la raza o la clase social han dejado de ser compartimentos estancos para hacer de la mutación y la duda su condición de existencia (p. 9).

Es opinión unánime de la crítica que la afirmación del erotismo singulariza la escritura de Di Giorgio con la consiguiente centralidad del cuerpo y la proliferación de cópulas, hibridismos y relaciones interespecies bajo los influjos y desbordes del deseo. Se trata de una perspectiva transgresora de prohibiciones, silencios y negaciones, por la liberación inquietante del deseo y el placer sexual que anuda vida y muerte, violencia y goce (Aira 2001; Vásquez 2008; Llurba 2009a, 2009b, 2010; Nespolo 2012). Este aspecto se ha leído como acorde con la conceptualización del erotismo de George Bataille, por su vinculación del placer como transgresión de la ley, dependiente por tanto de la conservación de la norma y de la unión de Eros y Thanatos, incluyendo la indefensión y sacrificio del cuerpo femenino ${ }^{1}$.

Desde una perspectiva deleuziana, Ana Llurba ha estudiado el tópico del erotismo en la obra narrativa de Di Giorgio bajo las categorías de lo anómalo -que daría la clave de una subjetividad arrastrada por un flujo de intensidades continuo y reversible entre lo humano, lo animal y lo vegetal (Llurba, 2009b, 2010)- y del deseo como producción, como energía que circula libremente entre los cuerpos de distintas especies y asume varias manifestaciones singulares, entre ellas la voz de un sujeto que deviene

\footnotetext{
${ }^{1}$ En Bataille el placer está inseparablemente ligado a la transgresión de la ley, es directamente proporcional al grado de transgresión de una ley que es su condición de posibilidad. Pienso, sin embargo, que el erotismo en la obra de Di Giorgio va más allá que la transgresión de la ley para la conservación y reafirmación de esta. En sus relatos encontramos un placer difuso, múltiple, entre seres no individuos que no aspiran a su disolución como tales, porque ya habitan en un mundo donde las barreras entre unos y otros no existen más.
}

68 | Alpha № 48 (JuLIO 2019) PÁGS. 67-83. ISSN 0716-4254 
mujer y crea un territorio de indiscernibilidad, de indistinción entre lo natural y lo fabril, escritura en que se diluye la oposición sujeto-naturaleza en el proceso de producción del deseo (Llurba, 2009a).

Desde que Ángel Rama la incluyera como sorprendente revelación en Aquí. Cien años de raros (1966), la crítica literaria ha persistido en adscribirla a una producción no canónica, inclasificable. Hugo Achugar (2005) postula que la obra de Marosa di Giorgio - en la que incluye sus performances- está atravesada por una diversidad de poéticas, entre las que se reconocen rasgos de la estética barroca o neobarroca, surrealista, kitsh y camp.

Para Bruña, este hibridismo genérico que rechaza las convenciones éticas y estético-literarias, sugiere una visión antiesencialista que expresa un "cuestionamiento ideológico a las categorías de control de la identidad y canalización del deseo" (2010, p. 226), ruptura que apunta especialmente, según Ferrús, a las identidades femeninas o "el sentido de la femineidad" (Ferrús, 2011, p. 50).

En relación con una crítica epistemológica, Vásquez (2008) ha señalado en la obra de Di Giorgio "un destierro de toda lógica, de toda racionalidad" (p. 265), mientras que Bruña ha situado su escritura en los límites epistemológicos posmodernos "en las fronteras epistemológicas de la posmodernidad" (Bruña, 2010, p. 227). Gabriel Giorgi, por su parte, incluye la obra de Di Giorgio entre los materiales de cultura que revisa como expresión de "otras modulaciones de saber y otros ejercicios éticos y políticos que devuelven a la vida su rareza inherente" (Giorgi, 2014, pp. 276-277); en el caso de la escritura marosiana, mediante la irrupción del animal testigo en las escenas de placer entre cuerpos atraídos por un deseo que desborda lo humano y cuya materialidad excede las normas de género, formulando otros principios de individuación, otras formas de pensar y realizar aquello que llamamos cuerpo y vida, bios como tejido de relaciones, entre-cuerpos (p. 275).

En esta línea, planteo que la obra de Marosa di Giorgio constituye una completa subversión y ruptura tanto epistemológica como de las estructuras de construcción de subjetividad, y que esta subversión se realiza a partir de la desarticulación del sistema de sexo-género-deseo por la total desestabilización de las categorías binarias y las lógicas del pensamiento racionalista y antropocéntrico para pensar la diferencia, desde donde se han construido los fundamentos de los órdenes políticos y simbólicos de Occidente. Dicho de otra manera, lo que quiero destacar es la enorme importancia e impacto que tiene la subversión de los órdenes de género en la desestructuración de los sistemas de conocimiento o lógicas de pensamiento convencionales y desarrollar un análisis de la medida en que la obra de Di Giorgio los des-vela como su piedra fundamental, tanto a nivel de motivos o temas como en su concepción del lenguaje literario. Desde este punto de vista, la práctica escritural proliferante, abierta a la mutabilidad y la multiplicidad -boda, misa, ritual-, permite leer los relatos eróticos de Di Giorgio como una escritura y una estética des-generada 
(Olea, 1998; Lozano, 2014; Escobar, 2016), que llama a "una lectura cómplice" (Olea, 1998) e interpela nuestra propia concepción del ejercicio crítico literario.

\section{EL MUNDO DE DIGIORGIO Y SUS HABITANTES}

La mayor parte de la crítica ha descrito el mundo de los textos marosianos como onírico, de referencia a la infancia, fantástico, fluido y ahistórico, donde prevalece lo orgiástico, las transformaciones, las metamorfosis, la proliferación (Bravo, 1997; Olivera-Williams, 2005; Vásquez, 2008; Canseco, 2010, 2013).

La crítica ha hecho notar también que este "mundo Marosa" es de manera deliberada rural y agrario. Los espacios que conforman el mundo de los relatos de Marosa di Giorgio son en su mayoría espacios naturales: jardines, bosques y huertas, rasgo que remite, ciertamente, a los espacios rurales habitados por la autora en su infancia, como ha reconocido en innumerables entrevistas, pero que está lejos de recrear de forma idealizada el mundo de la niñez. En una primera mirada, los habitantes de estos espacios parecen extraídos de los cuentos infantiles y de las fábulas: doncellas, animales y vegetales parlantes, ángeles, objetos animados; pero a pesar de su intemporalidad y de sus irreales personajes no se trata tampoco del mundo de los cuentos de hadas.

Es un mundo altamente complejo, en que todos sus componentes, todos los cuerpos humanos y no humanos, se encuentran energizados, movilizados, atraídos y electrizados por la corriente avasallante e imprevisible de la sexualidad y del deseo. Mundo hipersexualizado, mezcla de lo onírico y lo real; mundo en que ciertos "leitmotivs sexuales", verdaderas "obsesiones escriturales" (Bruña, 2010, p. 235), se escenifican una y otra vez: cópulas, pérdidas de la virginidad, fecundaciones, producción y expulsión involuntaria de huevos incubados, bodas sorpresivas, imprevistos actos o asaltos sexuales entre mujeres y hombres, pero también y muy frecuentemente, entre seres disímiles: entre mujeres o niñas y animales, mujeres y vegetales e incluso mujeres y objetos o seres invisibles e informes:

[...] Una fragancia de miel seguía brotando de su pequeña entrada.

Por la ventana cruzó una cosa. ¿Y eso? ¿Un trapo volando? ¿Una mariposa?

Venía derecho hacia el perfume y la entrada. Ella se reclinó de nuevo. Serían así las cosas. La segunda parte que habría, sería eso? ¿Lo dirigiría aquel que había estado?

(Misa final con alitas. Di Giorgio, 2008, pp. 57-58)

[...] En eso una voz partió del aparador y fue más fuerte que la alucinación. Expresó: - Soy la voz. Aquella que ya una tarde te conoció. Oye maravillosa. Oye. Me tornaré caballo. Lo que quieras. Si soy yo.

[...] La voz sin hacer caso fue directamente al hoyo entre las piernas y más adentro, a la encrucijada feroz. Y empezó a hacer. [...]

(Camino de las pedrerías, 43. Di Giorgio 2008, p. 201) 
Es una visión eminentemente antiesencialista que "da paso a lo inestable, lo indefinible o anómalo y los personajes son descritos o caracterizados por medio de lo polimorfo, lo variable, lo disperso" (Bruña, 2010, p. 236).

Seres que, por lo demás, sufren constantes transformaciones o metamorfosis; uniones y orgasmos que llevan a procrear no solo huevos, sino también conejitos, lagartos, flores y criaturas extrañas.

- Usted nunca tuvo hijos.

- No. Aunque un día, cuando era chica, surgieron de mí, de mi pelvis, tres lagartos. En cartílago grueso y anillado. Tres.

- Eh.

- Sí iban por la hierba. Al parecer tenían ojos, pero no pude saberlo. Se hundieron en el piso.

(Misal de la Virgen, Di Giorgio, 2008, p. 97)

[... ] No sé cómo cabía en el jardín. Si era un planeta! Y, sin embargo, estaba ahí. Luego de un rato de mirarlo mucho, lo abracé, me quité el vestido, tiré la rosa, lo abracé, lo abrazaba, con mis brazos y piernas y pequeñas tetas. Lo besé muchas veces.

Se me cayó algo del sexo, como un pimpollo, un huevo, se lo aplasté (con aroma a vida íntima), se lo refregué.

El planeta levitó, subió un poco, salió del suelo.

[...] Íbamos en el cielo; él hacía ahora un rumor raro, como si fuera un hombre, como si fuera un animal, o Dios. [...]

(Lumínile, 19. Di Giorgio, 2008, p. 290)

Para Cancellier (2015), en el mundo de "las identidades versátiles y camaleónicas" de Marosa di Giorgio, el huevo mantiene su significado de arquetipo por excelencia del nacimiento, "forma de la que nacen todas las formas posibles" y su simbolismo de transformación y renacimiento (p. 250). Este omnipresente núcleo generador, de posibilidades siempre abiertas e incesantes de mutación, prescinde del principio de identidad que rige en el orden racional del mundo para instalar el principio de lo múltiple, lo diverso y lo inestable. No se trata, sin embargo, de "un destierro de toda lógica, de toda racionalidad" (Vásquez, 2008, p. 265), sino de otro orden que supera las lógicas binarias y jerárquicas de la razón moderna y piensa de otro modo los ejes de identidad y diferencia. La propia autora afirma en una entrevista: "no creas, ese caleidoscopio guarda su orden" (Di Giorgio, 2010, p. 32).

TRANSFORMACIONES, MUTACIONES, METAMORFOSIS. DESARTICULACIÓN DE LOS EJES DE LA DIFERENCIA

Leemos en estas tramas y sus rupturas o disolución pavorosa-gozosa de límites de todo tipo, especialmente entre las dimensiones humanas y no humanas, una crítica y una subversión a ordenamientos de la realidad no solo androcéntricos, sino incluso a 


\section{María Teresa Aedo Fuentes}

conceptualizaciones antropocéntricas que imponen arbitrarios e interesados límites a la realidad material y humana.

La repetición de escenas, los “leit motivs sexuales” (Bruña) y traspasos de límites interespecies que señalamos, realizan una subversión que apunta a un tratamiento distinto de la diferencia, con una lógica que rompe los pares binarios y los modelos construidos sobre la oposición naturaleza/cultura. En efecto, es el mismo Binarismo Naturaleza/Cultura el que principalmente se desarticula en los relatos eróticos de Marosa di Giorgio: la recurrencia de inquietantes acoplamientos y entrecruzamientos entre lo material, lo natural no humano y lo humano logra derribar las, supuestamente, nítidas y definidas fronteras entre estas dimensiones.

Ella tenía un nombre muy bello -o a él le parecía-, señora Arabel. Y él se llamaba Maquinaria Agrícola. Qué espanto -se decía-, espiando con pasión hacia la casa. Como un ladrón o un enamorado espiaba. [...]

Su corpacho de hierro crujió un poco del gusto, la ansiedad, las oscuras ideas, entreabrió sus fauces de hierro. Hizo "Craac", "Arraac". Se dijo a sí mismo: Malditos fierros, soy de fierro.

(Misa y tractor. Di Giorgio, 2008, pp. 33, 34)

[...] Lo vi debajo de un árbol, velludísimo, en la luz y en la sombra de la mañana. Con un delantal granate algo estrafalario, que el viento movía a ratos. Usaba guampas, ojos oblicuos, fea nariz y boca igual, de la que salía, vi, cuando él quería, una lengua de un metro, roja y goteante, que podía quedar rígida y expectante. Como una rama con flor, de hibisco. [...]

(Camino de las pedrerías, 60. Di Giorgio, 2008, p. 231)

Esta difuminación de límites, que, interesa resaltar, no es en absoluto problemática para los personajes de los relatos, lejos de ser un rasgo propio de un mundo infantil fantástico e ilusorio, constituye, de acuerdo con Rosi Braidotti (2000), un esfuerzo que "implica transformar las estructuras e imágenes mismas del pensamiento y no solo el contenido proposicional del pensamiento" (p. 143). Asimismo, desde la crítica epistemológica propuesta por Donna Haraway (1995), las conceptualizaciones de "lo natural" y "lo humano" construyen límites que "tienen consecuencias en la conformación vital de cuerpos, significados y significados de cuerpos" (p. 34).

Contraviniendo el antropocentrismo del conocimiento occidental, en los relatos de Di Giorgio los animales no humanos y los objetos inanimados se hacen visibles y audibles, cobran vida, voz y acción - agentividad diría Haraway- saliendo de aquella mudez e invisibilidad en que los sumía la mirada "independiente" y "objetiva" del humano desde su autoasignada posición de poder. Esta invisibilidad de los otros, por lo demás, le es fundamentalmente requerida para sostener la propia vida del sujeto humano y la legitimidad de su poder-saber. En esto, la escritura de Marosa di Giorgio entronca con la crítica feminista y postcolonial del siglo XX a las formas limitadas y a la parcialidad de 
la "objetividad" y "transparencia" científica, tanto como a la neutralidad y universalidad eurocéntrica (Harding, 1997; Mohanty, 2008; Quijano, 2000; Lugones, 2011).

En suma, Di Giorgio desbarata los persistentes dualismos de las tradiciones occidentales, que, como nos recuerda Haraway (1995), son parte de "las lógicas y las prácticas de dominación de la naturaleza, las mujeres, las gentes de color, los trabajadores, los animales; en una palabra, la dominación de todos los que fueron construidos como otros, cuya tarea es hacer de espejo del yo" (p. 304). En el paradigma científico convencional, la figura de la Mujer se sitúa por el discurso en los límites entre lo natural y lo social (p. 34). En el análisis de Braidotti (2009), la Mujer es uno de los Otros que retorna desde los márgenes de silencio y exclusión de la modernidad.

Respecto de "los efectos históricamente específicos, cambiantes y cargados de poder de las 'diferencias' construidas por medio de múltiples campos sociales e imaginarios" (Haraway, 1995, p. 36s), es preciso recordar que el género "yace en el eje de las construcciones y de las clasificaciones de los sistemas de diferencia" en un orden eminentemente falogocéntrico (p. 219). Etimológicamente, incluso, el término género está asociado al verbo latino generare, engendrar, y a las nociones de especie, clase, que apoyan taxonomías y categorías biológicas (p. 219).

Políticas de género y políticas de la diferencia se encuentran estrechamente interconectadas, asumir la posibilidad de que "La naturaleza ya no es imaginada o puesta en marcha como un recurso para la cultura o el sexo para el género" (Haraway, 1995, p. 250), implica figurar otras formas de relación sexual y genéricas e imaginar otras formas de relacionamiento social. En los textos de Marosa di Giorgio junto con la disolución del binarismo Naturaleza/Cultura y la positividad de las identidades en constante cambio y transformación, se cuestiona también la noción de "identidad de género" y la distinción que opone sexo/género².

La dislocación entre sexo y género que encontramos en la obra de Di Giorgio, la inexistencia de una "esencia originaria" o de una "verdad natural" que determine la dirección del deseo, plantea una postura crítica rotunda frente a la normativa y las regulaciones del género. La construcción del sexo como categoría que fundamenta las relaciones de poder se constata y se evidencia en estos relatos como una ficción, o una invención fantástica que ya no puede producir el efecto de causalidad "natural" entre género y deseo (sexual), rompiendo la continuidad, la coherencia y el orden obligatorio de los ejes de sexo-género-deseo (Butler, 2007, pp. 54-56). De este modo, la obra marosiana no despliega una subversión mediante la liberación de un erotismo "femenino", que se mantendría por tanto dentro de los marcos de una norma y de una

\footnotetext{
${ }^{2} \mathrm{Si}$ bien en algún momento la distinción entre "sexo" como categoría biológica, estable y a-histórica frente a "género" como construcción social, histórica y cambiante significó un paso importante hacia la desnaturalización de las conceptualizaciones de género, muy pronto esta contraposición se develó atada al mismo sistema binario universalizante que pretendía impugnar y no significaba en modo alguno su superación. También era preciso "historiar" -al decir de Haraway (1995)- las categorías de sexo, cuerpo, biología, raza y naturaleza.
} 


\section{María Teresa Aedo Fuentes}

ley que lo produce y que lo supedita como fuerza libidinal, pues de ser así solo aparentemente se emanciparía de dicha ley y no haría más que ratificar los supuestos binarios de que surge. Di Giorgio va más allá, ya que no olvida que la sexualidad y el poder son coexistentes e interdependientes, no retrotrae el sexo a una libertad primigenia, anterior a la ley, sino que disocia ambos términos -sexo y género- y disloca la ley al relocalizar, al transponer sexo-género-deseo desbaratando los límites entre naturaleza y cultura, animado e inanimado, humano y no humano ${ }^{3}$.

Marosa Di Giorgio no parte de la idea de ningún original ni busca un estado final que pudieran servir de punto de referencia para alguna idea de "normalidad". Esto impactará a su vez en otros aspectos de las regulaciones de género, entre las que destaca la heterosexualidad normativa. Las mismas subversiones de límites entre animado e inanimado, humano y no humano vuelve in-válida, no pertinente la obligatoriedad de la heterosexualidad ${ }^{4}$.

[...] Pablo retomó el relato. Sus casamientos con Guinda en los jardines antiguos. Decía: - En la noche yo me transformaba en perro, y a mi ladrido acudía Guinda transformada en gata.

[...] Pero, igual florecía y me mostraba un botón rojo y me llamaba con la lengua fuera. Es muy singular su lengua. Es dura. Como si fuese de cerámica. Pero es ágil como la de un animal. A veces yo creía estar embarazado de ella.

(Camino de las pedrerías, 18. Di Giorgio, 2008, p. 161)

No solo ocurren sino que además se desean las frecuentes, placenteras y, es posible enfatizar, fecundas cópulas humana-animal, humana-vegetal y el autoerotismo. Señora da a luz conejitos, huevos, lagartos, tanto como extrañas criaturas no viables, dislocando la alineación Naturaleza-sexo-reproducción al transponerse los ya mencionados límites naturaleza/cultura, animado e inanimado, humano y no humano 5 . Las prácticas masturbatorias son altamente recurrentes en los relatos eróticos marosianos y prodigan también una notable capacidad de reproducción

\footnotetext{
${ }^{3}$ No se trata, pues, de una exaltación de la identidad femenina -la que se encuentra parodiada una y otra vez en la obra de Di Giorgio-, sí de una redefinición de la subjetividad femenina o de la emergencia de una subjetividad femenina en la línea propuesta por Braidotti, es decir, que procura evitar la trampa esencialista de una naturaleza femenina "auténtica" y que al mismo tiempo rechaza la idea de una neutralidad de la mente.

${ }^{4}$ Para María José Bruña, es posible leer la abolición de jerarquías y tabúes sexuales, así como las metamorfosis y transformaciones constantes en la obra y personajes de Di Giorgio como un cuestionamiento implícito de la heterosexualidad y una reivindicación de la autonomía sexual, especialmente femenina (Bruña, 2010, p.236). Bruña (2006) y Amícola (2013) se han detenido a estudiar los aspectos queer en la obra de Di Giorgio.

5 Es interesante recordar aquí la categoría de transposición de Rosi Braidotti para denominar un procedimiento que cruza límites a la vez que realiza saltos entre lugares de pensamiento o desde un código a otro, a la manera de los saltos de locus cromosómicos estudiados por la genética (Braidotti, 2009, p. 20). Sugiere una lectura de los relatos de Di Giorgio como un acto creativo de otras articulaciones de pensamiento y discurso, otro discurrir que brinca entre racionalidad e imaginación, más bien que una anulación de la razón o un estado prelógico (Bruña, 2010, p. 234).
}

74 | AlPHA No 48 (JuLIO 2019) PÁGS. 67-83. ISSN 0716-4254 
[...] Al entrar en la casa, vi que yo misma desovaba; me salía un huevo que recogí entre la piel y la bombacha. Lo miré; era celeste, magnífico, como de cristal y alabastro. Lo puse al pie de un espejo. Allí era doble. Sentí molestias también en los pechos. Entonces, quité mi ropa. Me practiqué los pechos como vi que había que hacer, y de allí salían dos huevecitos como dos fresas rojas, como de fulgurante vidrio.

(Camino de las pedrerías, 26. Di Giorgio, 2008, pp. 181-182)

En la obra de Marosa di Giorgio encontramos una visión que capta los cambiantes, incesantemente cambiantes límites de los objetos y de los seres, sugiriendo que su verdadera "naturaleza" es en realidad la capacidad infinita, inagotable, de transformación.

Asistimos a la paradoja de que se hace estallar el sentido por la repetición incansable y paródica de los mismos gestos -la superación de los binarismos de género por proliferación, como propone Butler (1999) que en cada repetición realiza una nueva mutación-. Una y otra vez lo que Bruña ha llamado "leitmotivs sexuales" destruyen toda fijación de significados por acumulación y reiteración para hacer imposible la estabilización.

No es, sin embargo, un mundo incoherente, sino la superación de una idea de mundo único y verdadero. Al decir de Haraway (1995), es "un desdoblamiento de los sentidos, una confusión de voz y visión" (p. 49) que propone una nueva, distinta racionalidad, abierta a la complejidad, la mutabilidad y la multiplicidad. Relaciones de género basadas en estructuras de diferencia y conexiones prolíficas y proliferantes, no dualistas, "monstruosas"; la búsqueda de identidades no dualistas de género de los sujetos humanos, y otras "configuraciones eróticas del deseo" (p. 49).

A la re-citación de normas morales y de resonancias religiosas respecto de cuerpos y relaciones, corresponde la incansable repetición de los rituales sensuales, sexuales, y ceremonias corporales que las subvierten hasta hacerlas estallar a la manera de una especie de performatividad de segundo grado que de-forma y transforma en habitual aquello que se erigía en acto sagrado especial.

Los rituales sexuales celebrados una y otra vez en los relatos marosianos se realizan ambiguamente como conjuro y parodia, como comunión y extrañamiento. El ritual no realiza sino más bien distancia de lo sagrado, se reitera como re-citación de un esquema de erotismo y sexualización que evidencia su artificiosidad y revela la medida en que se ha fundamentado un orden social en la asociación entre placer y dolor, erotismo y violencia. Es notable en este sentido el texto Misales (1993), que actualiza innumerables formas de ejercicio de la-supuestamente- sagrada violencia. $\mathrm{Al}$ respecto, en su lectura crítica de la noción de erotismo-trascendencia propuesta por Bataille, Braidotti hace notar que el sacrificio que da por condición necesaria siempre tiene como objeto el cuerpo femenino (Braidotti, 2009, p. 251), que hace parte de un poderoso discurso de legitimación de la violencia. 
BIOS Y ZOÉ

La búsqueda de otras relaciones, basadas en conexiones de configuraciones prolíficas y proliferantes, cala así más profundo en el cuestionamiento de las categorías binarias y las lógicas de pensamiento racionalista y antropocéntrico para pensar la diferencia, de modo tal que se aproxima a la noción de transposición, mutación y de un cierto vitalismo no esencialista que Rosi Braidotti recupera y reformula como el complejo bios/zoé.

Lo que "retorna" con el retorno de la Vida y de los "cuerpos reales" al final del posmodernismo y por el impacto de las tecnologías avanzadas, no solo es el otro del sujeto clásico de la modernidad: mujer/nativo/naturaleza. Lo que retorna ahora es el "otro" del cuerpo vivo en su definición humanista: la otra cara de bios, es decir, zoé, la vitalidad generadora de vida animal, no humana o prehumana. De acuerdo con esto asistimos a una proliferación de discursos que toman la Vida como un sujeto y no como el objeto de prácticas sociales y discursivas (Braidotti, 2009, p. 61).

La distinción tradicional según la cual "la vida es mitad animal, no humana (zoé), y mitad política y discursiva (bios)" y que reserva el control autorreflexivo acerca de la vida a los seres humanos, constituye la base del imperio de la cultura occidental, el hecho de que ambas dimensiones, pensadas como opuestas, coincidan en el cuerpo humano transformó la cuestión de la corporización en un espacio de pugna y en tablado político (Braidotti, 2009, p. 61) ${ }^{6}$. Al respecto, observa que esta complejidad es eludida por el dualismo mente-cuerpo, "introduciendo un criterio de distinción sexualizado, racializado y naturalizado" (pp. 61-62). En este esquema, lo que retorna es el DeseoZoé como cambio y fuerza transformadora de la vida:

Las mujeres fueron clasificadas junto con los aborígenes, los animales y otros como los referentes de una fuerza generadora reducida a una mera función biológica y privada de importancia política y ética. Hoy la política de la Vida misma rediseña esta Relación: debemos prestar atención a las fuerzas de la vida y la materia que están atravesadas -y no debidamente tratadas- por la política. Esto implica poner en el centro del escenario a zoé como relaciones o flujos de interacción, producción o poder generador y lo inhumano. Aceptar el bioigualitarismo de la política de zoé significa que se debe reconcebir a cada sujeto, más allá del sexo, la raza o la especie, de acuerdo con la positividad de la

\footnotetext{
${ }^{6}$ Es factible referir a la amplia discusión acerca de los planteamientos de Giorgio Agamben respecto del dispositivo biopolítico de la soberanía en torno a la distinción entre bios y zoé, especialmente de la diferencia semántica entre estos términos (véase, por ejemplo, los trabajos de Edgardo Castro, 2008, 2011, 2012). Al respecto, se debe señalar, que tanto Rosi Braidotti como Gabriel Giorgi se distancian de una interpretación de zoé como "nuda vida", o vida desnuda, asociada a falta de humanidad y a la muerte, para afirmar, en el caso de Braidotti (2009), la positividad, los poderes generativos de zoé como base de una ética de la sustentabilidad y, en Giorgi, la búsqueda de "epistemologías alternativas a toda diferenciación nítida, irrevocable entre bios y zoê' (Giorgi, 2014, p. 27).

76 | AlPHA № 48 (Julio 2019) PÁGS. 67-83. ISSN 0716-4254
} 
diferencia, esto es, la noción de diferencia entendida como el principio de no-Uno [...] (Braidotti, 2009, p. 366)

Es el advenimiento de zoé, como afirmación de un vitalismo no antropocéntrico, como una fuerza positiva y productiva no logocéntrica, donde lo que importa son las transformaciones, las transposiciones que se están produciendo sobre los ejes de la "diferencia" clásica, lo que permite afirmar una ética sustentable en un sujeto no unitario y un sentido de comunidad más amplio que abarca interconexiones territoriales que incluyen a los otros no humanos (Braidotti, 2009, p. 58).

Es posible enfatizar, también con Braidotti, que el juego de complejidades que introduce zoé no elimina las diferencias de poder, sino que las multiplica en torno a distintos ejes (p. 255). Son precisamente los espacios domésticos y rurales, no tecnologizados - excepto por el tractor, maquinaria agrícola-, los que también se muestran atravesados por el poder en la obra de Marosa. Comparto con Giorgi que el mundo literario de Di Giorgio es un mundo doméstico saturado de libido, donde el cuerpo y el placer femeninos son el punto de transmisión de todos los deseos, lo que pone en crisis instituciones como la conyugalidad (Giorgi, 2014, p. 271). No obstante, quiero enfatizar que si es el "punto de imantación" del Deseo, el cuerpo "femenino" es por tanto el punto de cruce del Poder y la subyugación -"domesticación"-, condición reiterada paródicamente hasta el hartazgo por los Misales de Marosa di Giorgio. Si, de acuerdo con el Diccionario de la Real Academia, "domesticar" significa en primera acepción: Reducir, acostumbrar a la vista y compañía del hombre al animal fiero y salvaje, entonces, cobra un nuevo y pleno sentido que la obra poética de Marosa di Giorgio quede recopilada con el título "Los papeles salvajes", esto es, artefacto aunque "no domesticado" (DRAE). Estamos nuevamente frente a una construcción paradójica de significados que resaltan y desatan los nudos y las contradicciones del poder.

Sabemos, con Braidotti, que históricamente, zoé fue feminizada, que las mujeres -junto con los aborígenes, los animales y la Naturaleza- fueron clasificadas como referentes de una fuerza generadora reducida a la calidad de mera reproducción biológica, sin ninguna relevancia política ni ética (Braidotti, 2009, p. 366). El hecho de que Marosa di Giorgio desarticule en su escritura los procedimientos legitimadores de relaciones de dominio - poder como potestas (Braidotti, 2009)- y, sobre todo las naturalizaciones de aquellas "verdades" evidentes, obvias, no solamente resignifica aquellas fuerzas vitales y generativas, sino que las politiza como potencialidades. Es una de las voces silenciadas que retorna.

En Formas comunes (2014) Gabriel Giorgi examina la dimensión política de materiales de la cultura que crean espacios de contestación a las condiciones tanto histórico-materiales como conceptuales y filosóficas que configuran marcos de inteligibilidad de la vida como humana y no humana (animal o no persona), de acuerdo con estos se trazan distinciones y jerarquías entre cuerpos y formas de vida. Desde este enfoque, percibe en Misales de Marosa di Giorgio (2008) una lógica de la multiplicidad que se sustrae a toda individualidad, atravesada por un deseo entre especies que inscribe 
otra lógica de cuerpos a partir de la presencia del tercero animal (pp. 269-277). Este tercero animal trae una corporalidad irreductible a la marca dual del género y producen otro saber, el del sexo como lo informe del cuerpo. La politización de la sexualidad, la constitución de lo sexual como hecho político, no puede ser sino esta experimentación que no es nunca reductible a una subjetividad y "su" cuerpo sino siempre, necesariamente, invención de nuevos espacios de relación, de nuevos modos de constituir un espaciamiento entre cuerpos" (Giorgi, 2014, p. 275-276).

En esta línea, es esencial preguntarse si esta multiplicidad y negación de un sustrato ontológico para la subjetividad-individualidad la realiza Marosa di Giorgio "a partir" de lo animal o esto es parte de la dislocación de las estructuras de saber que trazan el límite humano-no humano por el ejercicio de una imaginación que podríamos llamar con Rian Lozano (2014) "desgenerada". Creo más bien que se trata de esto último, sobre todo teniendo en cuenta que mujeres y animales comparten el clásico reino de zoé y que la escritura de Di Giorgio no solo in-corpora lo animal, sino también lo vegetal, los objetos, la voz, las almas, "eso", "algo".

Ya en 1993 y a propósito de la narrativa de Diamela Eltit, Raquel Olea denominaba como "de(s)generadas" aquellos cuerpos y existencias móviles y plurales, fuera de los regímenes ordenadores fijo y esencialistas de género (Olea, 1993, p. 88), y señalaba este proceso de (des)generamiento de órdenes de género-sexo como imprescindible para la construcción de nuevas identidades (Olea, 1998, p. 32). Igualmente, en sus estudios pertinentes a performances contemporáneas Rian Lozano (2014) aplica la noción de des-género que sintetiza tres aspectos que adquiere gran sentido en la lectura que hacemos de los relatos eróticos de Marosa di Giorgio:

De ahí que la propuesta de denominar 'de(s)generadas' a estas prácticas que nos interesan esconda un triple juego de palabras. Por un lado, y como ya hemos explicado, el 'des-género' implica un cuestionamiento de los géneros artísticos tradicionales [...]. A su vez, esta idea de des-género, unida a las nociones de performance y performatividad, nos va a servir para entender cómo algunas de las prácticas que nos interesan son herramientas útiles para desvelar $-\mathrm{y}$, en cierto sentido, desestabilizar- el funcionamiento normativo de los géneros sexuales. Por último, el 'degenero' hace referencia directa a esas ideas de decoro, ordenamiento e incluso moralidad que, respaldadas por la noción de belleza, han servido para construir ese mismo discurso artístico tradicional en Occidente (Lozano, 2014, pp. 69-70).

En un cuarto sentido posible, podemos hablar de una des-gener-acción, siguiendo la acepción de Maldonado (2007) como "acción que rompe con las relaciones dominantes coloniales de género" (p. 156), para referirnos tanto a la práctica escritural de Marosa di Giorgio como a la práctica crítica de lo que Raquel Olea (1998) llama "una recepción cómplice" (p. 43)7. La creación de mundos que ignoran las lógicas del

\footnotetext{
${ }^{7}$ En Lengua víbora (1998), Olea señala “[...] he insistido reiteradamente en la pregunta por la lectura como actividad política de productivización simbólica que se ejerce en el diálogo entre escritura ficcional o poética y 78 | AlPHA № 48 (Julio 2019) PÁGS. 67-83. ISSN 0716-4254
} 
poder normalizador sobre cuerpos y sujetos, sí como las leyes que ordenan el pensamiento, requieren ser leídos de modo no convencional, que no pretenda encerrarlo en categorías estables. Llama a una discusión no respecto de si leemos poesía o relato para constatar simplemente su hibridismo, sino a una reflexión acerca de qué implica una escritura que se desentiende totalmente de las categorizaciones literarias, tanto como de la distinción y relación entre ficción y realidad: "No elaboro nada; las cosas o las rosas me caen a la mano; esa es mi realidad y es mi irrealidad, dos palabras que, después de todo, nombran lo mismo" (Di Giorgio, 2010, p. 19). A la pregunta de si su poesía es imaginaria o realista, Di Giorgio responde "No veo la línea divisoria. Todo es como un retrato que fuera, a la vez, el original" (p. 26). Una escritura cuya puesta en práctica se rige por los principios de desplazamiento, movilidad, multiplicidad. "No me detengo. No cambio. Fijar lo errante, desatar lo fijo" (p. 38), no es solo un ejercicio de libertad creadora, sino también de acción liberadora que, al poner en cuestión los sistemas de construcción de significados, contiene, sin duda, una profunda dimensión política. En su estudio de la crítica literaria feminista en relación con las poéticas de narradoras latinoamericanas en tanto creación y construcción decolonizadora de conocimiento, Escobar plantea que es posible "reafirmar una cuestión innegable: las poéticas de-generativas son también políticas de-generativas; unos modos desviados de hacer política y de poner en discusión los regímenes de significación tradicionales que han permeado los estudios literarios" (Escobar, 2016, p. 87). De tal manera, desde nuestra recepción cómplice ponemos de relieve que la obra marosiana moviliza también la reflexión acerca de las relaciones entre literatura y política.

\section{PoÉTICA DE MAROSA DI GIORGIO: MISA-BODA CON EL LENGUAJE}

"Al fin, todo es una boda" (Di Giorgio, 2010, p. 32) expresa Marosa di Giorgio en una de sus entrevistas y "Todo se realiza en el lenguaje [...] La boda es con el lenguaje" (p. 117). Desde esta perspectiva ¿cómo pensar esta "boda con el lenguaje" que es la escritura de Di Giorgio? Es precisamente, creo, la tensión entre nombrar y un "algo" que permanece indecible, una práctica siempre excedida, una experiencia siempre localizada que no permitirá jamás develar el misterio.

Pero la poesía y todo el arte, ¿no es siempre una reinvención? No es una copia del mundo, porque es inapresable el mundo. Yo lo veo y lo transformo en escritura, y pongo cosas de mí. Eso queda como trasmutado. Porque veo las cosas y después aparecen como las mismas y de otro modo (Di Giorgio, 2010, p. 68).

Esta fuerza vital inapresable, remite en Marosa di Giorgio a la escritura poética, que dinamiza una nueva relación con lo inexpresable, lo indecible, imposible de poner en discurso y que se ejerce como práctica eminentemente creadora: "Mi escritura

escritura crítica, en la resemantización de signos que movilizan los significantes para, tendenciosamente, operativizar nuevos significados" (p. 43).

ALPHA No 48 (Julio 2019) PÁGS. 67-83. ISSN 0716-4254|79 
rememora la Creación, y aún unos instantes anteriores, cuando Dios no tenía nada totalmente delimitado. Y así, los claveles volaban y los pájaros nadaron. Sé que hay flores que irrumpen por todas partes. Pero, no creas, ese caleidoscopio guarda su orden" (2010, p. 32).

Esta relación con el lenguaje que no puede sino constituir un ritual: "Cumplo una misa, un extraño rosario, un sacrificio, un rito, se repite, y siempre es la primera vez" (Di Giorgio, 2010, p. 20). Un ritual, no obstante, que no tiene por objetivo instalar y reforzar una verdad, sino consagrar el acto creador de relaciones "posibles e imposibles" (p. 117). La Misa que es su escritura es una boda que une creatividad y disidencia: creatividad como imaginación de relaciones imprevistas, sorprendentes, inesperadas, impensadas y siempre provisorias e infinitas: "Lo que toco, lo que transito, cae en cenizas y, de inmediato, reaparece multiplicado y potenciado" (p. 33). Ese poder generador la convierte en druida, en "una dríade abrazada al árbol de la escritura que es el árbol de mi vida" (p. 152). El ejercicio de la creación poética en esa suerte de altar salvaje que es el lenguaje -"Marosa, la mantis religiosa, que tabletea su mensaje" (145) - se celebra como oficio, como saber, como poder: "Si fijo la atención en esa zona que yo sé, empiezan a aparecer cosas y cosas. Si quisiera estaría continuamente en la escritura. No te puedo explicar qué mecanismo es.[...] Es una habitación a la que tengo acceso (Di Giorgio, 2010, p. 69).

Y reclama una lectura igualmente creadora, en trance y tránsito: "Ese tránsito, ese trance, es el que acontece siempre, el que viene para estas cosas, ¿no?” (p. 69). Cocrear multiplicidades fuera de las lógicas y esquemas uno/otro, imaginar los cuerpos de otra manera para trans-formar las nociones de yo y otro, igual y diferente, reconocimiento y extrañeza. Es este un sentido profundo de las transformaciones y metamorfosis que atraviesan toda la obra de Di Giorgio.

\section{OBRAS CITADAS}

Agamben, Giorgio (2006). Homo sacer I. El poder soberano y la nuda vida. Valencia: Pre-textos.

Aira, César. (2001). Diccionario de autores latinoamericanos. Buenos Aires: Emecé, 173-174.

Amícola, José (2013). "El género queer de Marosa di Giorgio". Cuadernos del CILHA. Vol. 14, No 19: 153-165.

Braidotti, Rosi (2000). Sujetos nómades. Corporización y diferencia sexual en la teoría feminista contemporánea. Buenos Aires, Paidós.

— (2009). Transposiciones: Sobre la ética nómada. Barcelona, Gedisa.

Bravo, Luis (1997). "Las nupcias exquisitas: Marosa di Giorgio y el collage onírico". Cuadernos de Marcha, año XII, 129: 12-14. 
Bruña Bragado, María José (2010). "Raras criaturas: la audacia expresiva de Marosa di Giorgio". Cuadernos LIRICO 5, Raros uruguayos. Nuevas miradas: 223-240. http://lirico.revues.org/417. [En línea] Consultado 12 octubre 2012.

_ (2006). Maneras trágicas de "despertar" a una mujer: El matriarcado mítico de Marosa Di Giorgio. Encuentro de Latinoamericanistas Españoles (12. 2006. Santander): Viejas y nuevas alianzas entre América Latina y España, s.l., España. CEEIB, 2006: 1612-1619. Versión on line https://halshs.archivesouvertes.fr/halshs-00104676/. Consultado 12 octubre 2012.

Butler, Judith (1999). El género en disputa. Barcelona: Paidós Ibérica S.A., 2007.

Castro, Edgardo (2012). "Acerca da (Não) distinção entre Bíos e Zoé". INTERthesis: Revista Internacional Interdisciplinar, 9 (2): 51-61.

(2011). "El concepto de vida en Giorgio Agamben". R. Karmy Bolton, Ed Políticas de la Interrupción. Ensayos sobre Giorgio Agamben. Santiago de Chile: Escaparate: 83-112.

- (2008). Giorgio Agamben. Una arqueología de la potencia. Buenos Aires: UNSAM/Jorge Baudino.

Canseco, Adriana (2013a). "Éxtasis del lenguaje, éxtasis del pasado o la sincronía del poema. Reflexiones sobre el tiempo en la obra de Marosa di Giorgio". [En línea] URL:http://docplayer.es/37829544-Extasis-del-lenguaje-extasis-del-pasado-o-lasincronia-del-poema-reflexiones-sobre-el-tiempo-en-la-obra-de-marosa-digiorgio.html. Consultado 02 octubre 2016.

_ (2013b). "La disolución de las fronteras. Notas para pensar la "otra orilla" en la obra de Marosa di Giorgio". Cuadernos LIRICO. [En línea] URL: http://lirico.revues.org/934. Consultado 02 octubre 2016.

_ (2010). Volver al paraíso. Infancia y escritura en Marosa di Giorgio”. [En línea] URL: http://publicaciones.ffyh.unc.edu.ar/index.php/6encuentro/article/view/145. Consultado 20 mayo 2013.

Cancellier, Antonella (2015). "Los ojos de Amanda Berenguer y de Marosa di Giorgio para una exégesis de "El Jardín de las delicias" de El Bosco". Confluenze Vol. 7, No. 1: 247-259.

Di Giorgio, Marosa (2010). No develarás el misterio: entrevistas, 1973-2004. Compilación de Nidia di Giorgio. Buenos Aires: El Cuenco de Plata.

- (2008). El Gran Ratón Dorado, el Gran Ratón de lilas. Relatos eróticos completos. Buenos Aires: El Cuenco de Plata.

Echavarren, Roberto (1992). "Marosa di Giorgio, última poeta del Uruguay". Revista Iberoamericana, 58. (160), 1992: 1103-1115. [En línea] URL: https://doi.org/ 10.5195/reviberoamer.1992.5096. Consultado 14 mayo 2014.

Escobar Lastra, Carolina (2016). Poéticas y políticas de-generativas en tres narradoras latinoamericanas contemporáneas. Tesis para optar al grado de Doctora en Literatura Latinoamericana. Universidad de Concepción. Inédito. 
Ferrús, Beatriz (2011). "De 'género' dudoso: sobre la narrativa de Marosa di Giorgio". Mitologías hoy. Revista de pensamiento, crítica y estudios literarios latinoamericanos. Helena Usandizaga (editora), Universitat Autònoma de Barcelona: 50-59.

Giorgi, Gabriel (2014). Formas comunes: animalidad, cultura, biopolítica. Buenos Aires: Eterna Cadencia Editora.

Haraway, Donna (1995). Ciencia, cyborgs y mujeres. La reinvención de la naturaleza. Madrid: Cátedra.

Harding, Sandra (1997). Ciencia y feminismo. Madrid: Ediciones Morata.

Llurba, Ana (2010). "El erotismo en la narrativa de Marosa di Giorgio", Espéculo, Revista de Estudios Literarios, Universidad Complutense de Madrid. [En línea] URL: http://www.ucm.es/info/especulo/numero44/digiorgi.html.Consultado 12 oct. 2012.

— (2009a). "Devenir-mujer: la narrativa erótica de Marosa di Giorgio". Psikeba: Revista de Psicoanálisis y Estudios Culturales, №. 10, diciembre. [En línea] URL: https://psikeba.wordpress.com/2010/01/12/devenir-mujer-la-narrativa-erotica-demarosa-di-giorgio/. Consultado 12 octubre 2012.

_ (2009b) "La experiencia anómala del yo. El erotismo en Marosa di Giorgio", Konvergencias Literatura, Año III, $\mathrm{N}^{\circ}$ 10, mayo. [En línea] URL: www.konvergencias.net/anallurba127.pdf. Consultado 12 octubre 2012.

Lozano, Rian (2014). "Prácticas de(s)generadas: escenarios y cuerpos ambulantes". Investigación Teatral, Vol. 3, № 5: 61-77.

Lugones, María (2011). "Hacia un feminismo descolonial". La manzana de la discordia, julio-diciembre, Vol. 6, No. 2: 105-119.

Maldonado Torres, Nelson (2007). "Sobre la colonialidad del ser: contribuciones al desarrollo de un concepto". El giro decolonial. Reflexiones para una diversidad epistémico más allá del capitalismo global, Santiago Castro-Gómez y Ramón Grosfoguel (eds.). Bogotá: Siglo del Hombre: 127-168.

Mohanty, Chandra Talpade (2008). "Bajo los ojos de occidente. Academia Feminista y discurso colonial”. En Liliana Suárez Navaz y Aída Hernández (editoras): Descolonizando el Feminismo: Teorías y Prácticas desde los Márgenes, ed. Madrid: Cátedra: 117-164.

Olea, Raquel (1998). Lengua víbora/ producciones de lo femenino en la escritura de mujeres chilenas. Santiago: Cuarto Propio.

__ (1993). "El cuerpo-mujer. Un recorte de lectura en la narrativa de Diamela Eltit". Lértora, Juan Carlos (ed.), Una poética de literatura menor. Santiago de Chile: Cuarto Propio: 83-96.

Olivera-Williams, María Rosa (2005). "la imaginación salvaje: Marosa di Giorgio" Revista Iberoamericana, Vol. LXXI, № 211, abril-junio: 403-416. 
Quijano, Aníbal (2000). "Colonialidad del poder, eurocentrismo y América Latina”, en Edgardo Lander (ed.). La colonialidad del saber: eurocentrismo y ciencias sociales. Perspectivas latinoamericanas, Caracas: IESALC-Instituto para la Educación Superior en América Latina y el Caribe: 201-246.

Vásquez Rodríguez, Gilberto (2008). "El esplendor de las metamorfosis: erotismo fantástico en la literatura de Marosa di Giorgio". Anales. Lo fantástico: Norte y Sur. $\mathrm{N}^{\circ}$ 11: 261-282. [En línea] URL: https://gupea.ub.gu.se/bitstream/2077/ 10423/1/gupea_2077_10423_1.pdf 